\title{
Mujer mapuche y retos de la justicia intercultural: aplicación del derecho propio indígena en delitos de violencia intrafamiliar
}

\section{Intercultural justice challenges and the Mapuche women: indigenous law in domestic violence cases}

\author{
Rosario Palma Ayala
}

Universidad Central de Chile, Chile

Egresada de derecho de la Universidad Central de Chile. Ayudante de investigación del proyecto "Bases de sustentación de justicia comunitaria indígena en Chile. Especial referencia al caso mapuche", de la Vicerrectoría académica de investigación de la Universidad Central de Chile.

rosariop.ayala@gmail.com

\section{Renata Sandrini Carreño}

Universidad de Chile, Chile

Abogada de la Universidad de Chile. Ayudante de investigación del proyecto "Bases de sustentación de justicia comunitaria indígena en Chile. Especial referencia al caso mapuche", de la Vicerrectoría académica de investigación de la Universidad Central de Chile.

renata.sandrini.6@gmail.com

\section{RESUMEN}

Este artículo analiza la manera en que los tribunales chilenos han aplicado el derecho propio indígena en casos de violencia intrafamiliar donde las víctimas son mujeres pertenecientes al pueblo mapuche. Se reflexiona en torno a la relación entre el derecho propio indígena y la respuesta estatal, planteándose que la respuesta que han dado los tribunales de justicia, respecto a que existe una colisión entre los derechos de las mujeres y los derechos de los pueblos indígenas, es aparente, existiendo alternativas de solución que respetan de manera integral los derechos de las mujeres mapuche.

Palabras clave: Violencia contra la mujer - acuerdos reparatorios - justicia intercultural -pueblos indígenas.

\begin{abstract}
The article analyses how Chilean courts have applied the indigenous law to domestic violence cases where the victims are Mapuche women. It discusses the relationship between indigenous law and the State response suggesting that the treatment given by the courts to the clash between women's rights and indigenous law is apparent, because there are solutions that fully respect the rights of the Mapuche women.
\end{abstract}

Key words: Violence against women - reparation agreements- intercultural justice - indigenous people. 


\section{Introducción}

El presente artículo aborda la problemática del reconocimiento del derecho propio indígena desde una perspectiva de género. Particularmente, se realiza un estudio de doce casos conocidos y sentenciados por la Corte de Apelaciones de Temuco ${ }^{1}$, en que se consideran procedentes los acuerdos reparatorios en casos de violencia intrafamiliar entre víctimas e imputados pertenecientes al pueblo mapuche, pese a que esta salida alternativa está expresamente prohibida para este tipo de ilícitos, según lo prescrito en el artículo 19 de la Ley No. 20.066 de Violencia Intrafamiliar (en adelante, Ley VIF); bajo el fundamento de la necesidad de respetar la costumbre indígena en virtud del Convenio 169 de la OIT.

En primer lugar, se plantea el problema, dando cuenta del estado actual de la jurisprudencia en la materia. A continuación, y con el propósito de plantear posibles soluciones, se hará un análisis de los límites al derecho consuetudinario indígena desde una perspectiva de los derechos humanos, en particular, desde los derechos de las mujeres a una vida libre de violencia. Asimismo, se expondrán las formas en que se conciben y se dan solución a estos conflictos en la cosmovisión mapuche. Finalmente, a la luz de estas consideraciones, se planteará que no existen soluciones dicotómicas en la materia y que es posible conciliar de manera integral los derechos de la mujer mapuche.

Para elaborar el presente artículo, se realizó una investigación práctica aplicada de nivel exploratoria, con la intención de obtener conocimiento sobre la relación del derecho propio indígena con la respuesta que el sistema entrega a las mujeres mapuche víctimas de violencia intrafamiliar. Especial relevancia cobran en este artículo y en la búsqueda de soluciones al conflicto, los testimonios recolectados a través de entrevistas realizadas en el marco de la presente investigación a nueve mapuche de los lof Kurrache, Muco Bajo, Temucuicui, Temulemu, Yeupeco y Galvarino, todos de la región de la Araucanía. Entre los entrevistados se encuentran tres comuneras, un werken, un lonko, un kimche, un futuro lonko y un consejal².

\section{Planteamiento del problema: aplicación de acuerdos reparatorios en casos de violencia in- trafamiliar entre personas pertenecientes al pueblo mapuche}

Los casos que inspiran la presente investigación, son aquellos en que ha existido la aplicación de acuerdos reparatorios en causas sobre violencia intrafamiliar entre víctimas e imputados pertenecientes al pueblo mapuche, pese a que la Ley VIF prohíbe de manera expresa estos acuerdos en su artículo $19^{3}$. En efecto, la procedencia de acuerdos reparatorios en materia de VIF fue prohibida "puesto que el consentimiento para la celebración de un acuerdo reparatorio no puede ser prestado libremente por la persona que ha sido víctima de delitos precedidos de violencia intrafamiliar, ya que ésta se encuentra normalmente muy disminuida en su autoestima y no está en condiciones de negociar en igualdad de condiciones" ${ }^{\prime 4}$. Lo señalado por el legislador chileno, ha

Corte de Apelaciones de Temuco. Sentencia de 5 de marzo de 2012. Rol 169-2012; sentencia de 2 de agosto de 2012. Rol 581-2012; sentencia de 19 de enero de 2012. Rol 18-2012; sentencia de 23 de noviembre de 2012 . Rol 1034-2011; sentencia de 4 de enero de 2011. Rol 1192-2011; sentencia de 17 de julio de 2012. Rol 499-2012; sentencia de 19 de diciembre de 2012. Rol 995-2012; sentencia de 18 de diciembre de 2012. Rol 970-2012; sentencia de 21 de agosto de 2012. Rol 635-2012; sentencia de 27 de octubre de 2012. Rol 955-2011; sentencia de 4 de junio de 2012. Rol 388-2012 y; sentencia de 24 de enero de 2012. Rol 43-2012.

Durante la investigación también se realizaron entrevistas a otros operadores de la Región de la Araucanía, entre ellos, dos jueces de garantía, dos jueces de Tribunal Oral en lo Penal, cuatro fiscales, tres defensores penales, dos facilitadoras interculturales y una profesional de la Corporación de Asistencia Judicial.

Artículo 19 Ley VIF "Improcedencia de acuerdos reparatorios. En los procesos por delitos constitutivos de violencia intrafamiliar no tendrá aplicación el artículo 241 del Código Procesal Penal".

Biblioteca del Congreso Nacional. Historia de la Ley No. 20.066, p.408. Disponible [en línea] <http://www.leychi- 
sido ampliamente reconocido por la doctrina y jurisprudencia internacional, que advierte de los peligros del uso de la conciliación como método para resolver casos de violencia doméstica, por cuanto "la conciliación asume que las partes involucradas se encuentran en igualdad de condiciones de negociación, lo cual, generalmente, no es el caso en casos de violencia intrafamiliar" ${ }^{\prime \prime}$.

En el caso chileno, la situación que se ha dado y que ha justificado la aplicación de acuerdos reparatorios, puede ejemplificarse de la siguiente manera: una mujer mapuche maltratada por su conviviente también indígena, recurre a los tribunales chilenos en busca de justicia. Posteriormente, se formaliza la investigación en contra del agresor por un delito en contexto de violencia intrafamiliar. La Defensoría Penal Mapuche solicita como salida alternativa un acuerdo reparatorio ${ }^{6}$, en aplicación de los artículos 9 y 10 del Convenio 169 de la OIT $^{7}$. El Ministerio Público se opone, argumentando que esta salida alternativa está prohibida en casos de violencia intrafamiliar por expresa disposición del artículo 19 de la Ley VIF. Por su parte, la víctima acepta esta forma de resolución del conflicto y, finalmente, el tribunal de primera instancia aprueba el acuerdo fijando como medidas reparatorias pedir disculpas públicas, comprometerse a no reiterar los hechos y asistir a terapia familiar, entre otras.

Conociendo de estas causas en recursos de apelación deducidos por el Ministerio Público, los tribunales superiores han sostenido sistemáticamente lo siguiente:

Que en este sentido, es un hecho público y notorio en esta Región, que las personas de la etnia mapuche, históricamente han resuelto sus conflictos, incluso algunos de mayor gravedad que los que motivan esta causa, mediante la negociación, por cuanto es propio de su cultura resolver de esta manera los conflictos, razón por la cual resulta plenamente aplicable el Convenio 169 ya referido por sobre la Ley 20.0668.

En este sentido, los tribunales superiores de justicia, asumiendo que la negociación es el método de resolución de conflictos que se identifica con la costumbre indígena, permiten la proceden-

le.cl/Navegar?idNorma=242648> [consulta: 24 de marzo de 2014].

$\mathrm{CIDH}$. Acceso a la justicia para mujeres víctimas de violencia en las Américas. OEA/Ser.L/V/II., doc. 68, 20 de enero de 2007, párr. 161. Además, respecto de las particularidades de la violencia doméstica contra la mujer y cómo estas inciden en la falta de capacidad de negociación directa entre víctima y agresor, consúltese ampliamente: RIOSECO, Luz. "Mediación en casos de violencia doméstica". En: FACIO, Alda. Género y derecho. Santiago: LOM ediciones, 1999, pp. 575-611 y RIOSECO, Luz. Informe sobre violencia intrafamiliar en Chile. Santiago: Fundación Pro Bono, 2004, disponible [en línea] <https:/www.u-cursos.cl/derecho/2004/2/D121D0328/10/material_docente/objeto/46121> [consulta: 10 de marzo de 2014].

6 El acuerdo reparatorio es una salida alternativa al proceso penal, cuya procedencia está reglamentada en el artículo 241 del Código Procesal Penal chileno, el cual dispone que: "El imputado y la víctima podrán convenir acuerdos reparatorios, los que el juez de garantía aprobará, en audiencia a la que citará a los intervinientes para escuchar sus planteamientos, si verificare que los concurrentes al acuerdo hubieren prestado su consentimiento en forma libre y con pleno conocimiento de sus derechos. Los acuerdos reparatorios sólo podrán referirse a hechos investigados que afectaren bienes jurídicos disponibles de carácter patrimonial, consistieren en lesiones menos graves o constituyeren delitos culposos. En consecuencia, de oficio o a petición del ministerio público, el juez negará aprobación a los acuerdos reparatorios convenidos en procedimientos que versaren sobre hechos diversos de los previstos en el inciso que antecede, o si el consentimiento de los que lo hubieren celebrado no apareciere libremente prestado, o si existiere un interés público prevalente en la continuación de la persecución penal".

Artículo 9 Convenio 169 de la OIT "1. En la medida en que ello sea compatible con el sistema jurídico nacional y con los derechos humanos internacionalmente reconocidos, deberán respetarse los métodos a los que los pueblos interesados recurren tradicionalmente para la represión de los delitos cometidos por sus miembros. 2. Las autoridades y los tribunales Ilamados a pronunciarse sobre cuestiones penales deberán tener en cuenta las costumbres de dichos pueblos en la materia"; artículo 10 Convenio 169 de la OIT "1. Cuando se impongan sanciones penales previstas por la legislación general a miembros de dichos pueblos deberán tenerse en cuenta sus características económicas, sociales y culturales. 2. Deberá darse la preferencia a tipos de sanción distintos del encarcelamiento". 
cia de acuerdos reparatorios basándose en el Convenio 169 de la OIT.

Frente a la respuesta entregada por la magistratura, surgen diversas interrogantes que se relacionan con la integración armónica de diversos estatutos normativos: ¿existen límites al derecho propio al hablar de relaciones de género e interculturalidad?, ¿es patente una colisión entre los derechos de la mujer como tal y sus derechos como mujer indígena?, ¿cuáles son las vías idóneas para la solución de estos conflictos? En torno a estas interrogantes se han otorgado diversas soluciones -que veremos más adelante- acerca de cuál debe ser la respuesta estatal frente a conflictos en que estén involucrados los derechos de las mujeres pertenecientes a pueblos indígenas. A continuación, exploraremos algunos elementos que nos parecen fundamentales para dar respuesta a estas preguntas.

\section{Límites a la costumbre y derecho consuetudinario indígena frente al derecho de la mujer a una vida libre de violencia}

Existe consenso a nivel internacional, respecto a que el límite a la aplicación de la costumbre indígena se encuentra en los derechos humanos. ${ }^{9}$ El Convenio 169 establece un criterio "acumulativo de excepción"10 en los artículos 8 y 9, señalando que deberá respetarse o tomarse en consideración el derecho consuetudinario indígena mientras no sea incompatible con los derechos humanos fundamentales que estén reconocidos internacionalmente. Así, "las disposiciones legales nacionales que son incompatibles con derechos reconocidos bajo el Derecho Internacional de los Derechos Humanos no pueden ser usadas para justificar la ignorancia de las costumbres de los pueblos indígenas en la aplicación de la legislación nacional; por otra, las costumbres indígenas no pueden constituir justificación para la violación de los derechos humanos fundamentales"11.

No obstante, la expresión "derechos humanos reconocidos internacionalmente" genera debates en cuanto a su amplitud y límites respecto a los derechos de los pueblos indígenas. En este sentido, se ha señalado que "es posible, [...] encontrar un mínimo consenso sobre la necesidad de vigencia de los derechos humanos y las libertades públicas en toda cultura y tradición, aunque dicho mínimo consenso se centre en un ámbito muy estricto y con interpretaciones diferentes ${ }^{\prime 12}$. El problema surge al intentar llegar a ese mínimo consenso y apartar el grupo de derechos que "se le debe reconocer a todo ser humano cualquiera que sea el sistema normativo y cultural en que se desenvuelva"13. El profesor Borja Jiménez afirma que "todo sistema de convivencia ha de concebir al hombre como agente moral, y de ahí se deduce que uno de los postulados básicos del consenso intercultural sea el respeto al principio de autodeterminación, de autonomía de la persona [...]. De aquí se derivan algunos derechos íntimamente ligados a este reconocimiento de carácter universal, cuales son el derecho a la vida, a la integridad física, a la libertad de ex-

En este sentido véase: BORJA, Emiliano. Introducción a los Fundamentos del Derecho Penal Indígena. Valencia: Tirant lo Blanch, 2001, pp. 179 y 190 y LILLO, Rodrigo. El Convenio 169 de la OIT y la defensa penal de indígenas. Minuta Regional No.1. Santiago: Defensoría Penal Pública, 2010, p.7. Disponible [en línea] <http://www.dpp.cl/ resources/upload/093e523d3fa9fe3d8745793ada63a58b.pdf > [consulta: 11 de marzo de 2014]. En el mismo sentido véase el artículo 34 de la Declaración de la Naciones Unidas sobre los Derechos de los Pueblos Indígenas y, Corte IDH. Caso Yatama vs. Nicaragua. Excepciones Preliminares, Fondo, Reparaciones y Costas. Sentencia de 23 de junio de 2005. Serie C No. 127, párr.225.

LILLO, Rodrigo. El Convenio $169 \ldots$ op. cit., p. 7.

11 Ibídem, p.8. En el mismo sentido se pronuncia el artículo 34 la Declaración de Naciones Unidas sobre los Derechos de los Pueblos Indígenas. 
presión y de asociación y a la seguridad"14.

La jurisprudencia de la Corte Constitucional de Colombia es un ejemplo de cómo se han intentado resolver estos conflictos. En un caso emblemático, considera que "solo con un alto grado de autonomía es posible la supervivencia cultural" y concluye que debe asumirse una postura interpretativa que permita "la maximización de la autonomía de las comunidades indígenas y, por lo tanto, [...] la minimización de las restricciones a las indispensables para salvaguardar intereses de superior jerarquía"15. Sobre la base de estas consideraciones, otorga una pauta para resolver estos conflictos:

[...] al ponderar los intereses que puedan enfrentarse en un caso concreto al interés de la preservación de la diversidad étnica de la nación, sólo serán admisibles las restricciones a la autonomía de las comunidades, cuando se cumplan las siguientes condiciones:

a. Que se trate de una medida necesaria para salvaguardar un interés de superior jerarquía (v.g. la seguridad interna).

b. Que se trate de la medida menos gravosa para la autonomía que se les reconoce a las comunidades étnicas ${ }^{16}$.

Por ello, la Corte Constitucional plantea que el núcleo de derechos intangibles incluye solo el derecho a la vida, la prohibición de la esclavitud y prohibición de la tortura. Las razones que se arguyen son que solo respecto a estos derechos fundamentales existe un verdadero consenso intercultural, y que se trata del núcleo de derechos que no pueden ser desconocidos bajo ninguna circunstancia, ni siquiera en situaciones de conflicto armado ${ }^{17}$. Así lo reconocen numerosas convenciones y tratados internacionales ${ }^{18}$.

En el caso específico de los límites a la costumbre desde la perspectiva de los derechos de la mujer, la comunidad internacional ha reconocido que la violencia contra la mujer es una violación de derechos humanos ${ }^{19}$, aunque se intente justificar en prácticas culturales o religiosas. Sin embargo, "cada vez más se emplean paradigmas relativistas culturales y políticas de identidad para restringir en particular los derechos de las mujeres. También se utilizan interpretaciones esencialistas de la cultura para justificar la violación de los derechos de la mujer o para condenar [...] culturas 'de otros' por ser intrínsecamente primitivas y violentas hacia las mujeres" ${ }^{20}$. De esta forma, las interpretaciones esencialistas olvidan que el modelo patriarcal es un legado que

14 Ídem.

15 Corte Constitucional de Colombia. Sentencia de 8 de agosto de 1996. T-349/96, párr.2.2.

16 Ídem.

17 Ibídem, párr. 2.3.

18 Artículo 27 de la Convención Americana sobre Derechos Humanos, artículo 2 de la Convención contra la Tortura y Otros Tratos o Penas Crueles Inhumanos o Degradantes y artículo 4 del Pacto de Derechos Civiles y Políticos.

Por ejemplo, la Declaración sobre la Eliminación de la Violencia contra la Mujer, en su artículo 4 dispone que: "Los Estados deben condenar la violencia contra la mujer y no invocar ninguna costumbre, tradición o consideración religiosa para eludir su obligación de procurar eliminarla [...]". También puede consultarse: Consejo de Derechos Humanos. Informe del Relator Especial sobre los derechos de los pueblos indígenas, James Anaya, resolución A/HRC/21/47, 6 de julio de 2012, párrs. 21-33.

Consejo de Derechos Humanos. Intersecciones entre la cultura y la violencia contra la mujer: informe de la Relatora Especial sobre la violencia contra la mujer, sus causas y consecuencias, Yakin Ertürk, resolución A/HRC/4/34, 17 de enero de 2007. Disponible [en línea] <http://www.acnur.org/t3/fileadmin/scripts/doc.php?file=biblioteca/ pdf/5135> [consulta: 11 de marzo de 2014]. Véase también: Consejo Económico y Social de Naciones Unidas. Integración de los derechos humanos de la mujer y la perspectiva de género: la violencia de género, resolución E/CN.4/2003/75, 6 de enero de 2003, disponible [en línea] <http://www.unhchr.ch/Huridocda/Huridoca.nsf/0/ eb34ca65984f9cb3c1256ce00059768b/\$FILE/G0310099.pdf> [consulta: 24 de marzo de 2014]. 
ha permeado y que puede estar presente en todas las culturas, por lo que la lucha por erradicar la violencia contra la mujer no debe ser encubierta bajo el respeto de la diversidad cultural y religiosa, sino que se debe avanzar en tomar conciencia acerca de las causas de la violencia, con el objeto de lograr un real reconocimiento de los derechos de las mujeres indígenas.

\section{Az Mapu ${ }^{21}$ y el derecho de la mujer mapuche a una vida libre de violencia}

Al analizar los límites a la costumbre indígena desde la perspectiva de los derechos de las mujeres a una vida libre de violencia, es necesario dar cuenta de cómo se entiende la violencia contra la mujer, sus causas y formas de enfrentarla en la cosmovisión mapuche, con el objeto de determinar si la respuesta estatal a estos conflictos ha sido adecuada.

Una investigación realizada el año 2008 por la Corporación de Servicio y Asesoría Técnica y de Desarrollo de Mujeres Mapuche "Aukiñko Zomo", titulada "Estudio comparado sobre violencia intrafamiliar en seis comunas de la provincia de Cautín" ${ }^{\prime 2}$, concluye que los hombres y mujeres mapuches identifican principalmente la violencia intrafamiliar con la agresión física y verbal y que sus desencadenantes son el consumo de alcohol, seguido por los celos y el "machismo". Más del setenta por ciento de las víctimas son mujeres y sobre el cincuenta por ciento de las y los entrevistados dijeron conocer a alguien víctima de VIF. Estas cifras y percepciones son similares a las de los hombres y mujeres no mapuche encuestados en nuestro estudio.

De lo anterior, se infiere que la significación de la violencia intrafamiliar, sus causas, frecuencia y víctimas dentro del pueblo mapuche, no difieren sustancialmente de lo que acontece en la realidad winka ${ }^{23}$.

Por otra parte, dentro de la cosmovisión mapuche, que asigna un rol fundamental a la familia, la violencia contra la mujer no es esencial ni natural a la cultura. De ello da cuenta el siguiente testimonio:

[...] cuando se casa una persona mapuche con otro mapuche hay un consejo, un lam, de nuevo el consejo, ahí aconsejan dos mujeres ¿cierto?, dos mujeres más abuelitas de la comunidad y dos hombres para el hombre y ahí dicen que se demoran un día aconsejándolos, que tiene que ver con los valores, como criar a los hijos, como respetar a su mujer, como hacer vida en el territorio, su cultura. Para la mujer todos sus roles de mujer por las mujeres y para el hombre todos los roles del hombre por los hombres. Por supuesto a nadie se le dijo usted va a golpear a su mujer, eso es muy mal visto en la familia. Si después llega eso, existía otra forma de resolverlo. Pero no es que en general la violencia se dé. Porque yo escuché la otra vez, o sea hubo una reunión con la encargada del SERNAM de la Araucanía por algunos casos, ellos querían aplicar la ley porque dicen que los mapuche son súper violentos y la violencia intrafamiliar, pero era un discurso feminista y ese tema no es de los mapuche, los mapuches el rol de la mujer esta clarito y el del hombre igual, porque nuestra cultura es así, nuestro Küyen dirige la vida

21 "El Az-Mapu es la esencia de la tierra, el rostro, la imagen de toda la naturaleza, su lectura, su ser, su vida, eso es Az-Mapu. Es por tanto el código de ética y comportamiento del hombre Mapuche, respecto de la naturaleza y toda su esencia de ser. Esto harás. Esto no harás. De esta forma lo harás. Si yerras tienes esta posibilidad de enmendar. El procedimiento, la metodología, los pasos de los rituales, las condiciones de los rituales, los elementos integrantes que deben participar, todo, todo está descrito." En: ÑANCULEF, Juan. "La cosmovisión y la filosofía mapuche: Un enfoque del Az-Mapu y del Derecho Consuetudinario en la cultura Mapuche". Revista de Estudios Criminológicos y Penitenciarios, Vol. 6, 2003, pp. 38-57.

Corporación Aukinko Zomo. Estudio comparado sobre violencia intrafamiliar en seis comunas de la provincia de Cautín. Temuco: Servicio de Salud Araucanía Sur, 2008. Disponible [en línea]: <https://www.araucaniasur.cl/fileadmin/documentos_ssas/INFORME_FINAL_VIF.pdf> [consulta: 1 de octubre de 2013]. No mapuche. 
de la luna en ese caso a la mujer y el sol al hombre, se da hasta en nuestra cosmovisión propia mapuche. Entonces eso de la violencia si se da, no podemos desconocer, pero hay formas, para eso están los adultos, para eso están las familias, un tío mayor, una tía mayor que va a ir a aconsejar y esta, se da al interior de las comunidades. Está hoy día presente, muy presente ${ }^{24}$.

Por otra parte, si bien se coincide en que la violencia contra la mujer está presente, hay referencias a que la inclusión de elementos foráneos ha permitido la internalización de esta violencia dentro del mundo mapuche. Se menciona la religión, el alcohol, instituciones externas, entre otras, que han permeado las costumbres mapuches. El siguiente testimonio es reflejo de lo aquí señalado:

\begin{abstract}
Nuestra gente era armónica con la naturaleza, los animales, la biodiversidad. La violencia es una cosa ajena que se fue entrando a la comunidad con la colonización, con la ideología, con la religión, la situación política, el empobrecimiento, con la pérdida de los recursos propios del territorio, con la invasión se fue arraigando la violencia, entrando en nuestro pueblo [...] y el hombre empezó a tomar vino, a embriagarse, se empieza a perder el respeto y lamentablemente [a] las mujeres, le[s] ha llegado la peor parte porque el hombre impositivo, con el alcohol doblemente impositivo, ha ido maltratando, nuestra gente ha ido como acostumbrándose a vivir así $[\ldots]^{25}$.
\end{abstract}

Así, aunque en la memoria comunitaria y en la costumbre ancestral, la violencia contra la mujer se identifica como un fenómeno negativo que afecta el equilibrio de la familia y la comunidad, en las prácticas actuales, los procesos de aculturización han influido en la internalización de la violencia ${ }^{26}$.

En cuanto a la manera en que se abordan estos $\operatorname{conflictos}^{27}$, las experiencias analizadas indican que no existe en el Az Mapu un sistema único de resolución de controversias para estos casos, sino que este varía en cada comunidad. Sin embargo, existen algunos criterios mínimos que son comunes a las diversas comunidades. El más relevante es la intervención de un tercero en la resolución del conflicto. En efecto, en algunos $l o f^{28}$ se recurre al longko ${ }^{29}$, a los ancianos de la familia, a la familia en su conjunto, a los tíos y tías, entre otros.

24 Entrevista a comunera mapuche de la comunidad Ankapi Ñancucheo, Lof Kurreche realizada el 20 de julio de 2013 en la comuna de Ercilla, Chile. Entrevista efectuada en el marco del proyecto de investigación "Bases de sustentación de la justicia comunitaria indígena en Chile. Especial referencia al caso mapuche".

Entrevista a María Isabel Curihuentro Llancaleo. En: MERCADO, Ximena. Violencia hacia la mujer y az mapu, sistema jurídico mapuche: reflexiones y perspectivas. Investigación realizada en el contexto del diplomado "Fortalecimiento del liderazgo de las mujeres indígenas", Fondo Indígena y Universidad Indígena Intercultural, 2011, p.36. Disponible [en línea] <http://www.fondoindigena.org/apc-aa-files/11 cff670a2ec169cc25379afa3d771db/58. pdf> [consulta: 11 de marzo de 2014]

26 Ver ibídem y PAINEMAL, Millaray y RICHARDS, Patricia. "Transnacionalización, derechos humanos y mujer mapuche". En: CHENAUT, Victoria (et.al). Justicia y diversidad en América Latina: pueblos indígenas ante la globalización. México D.F: Centro de Investigaciones y Estudios Superiores en Antropología Social - FLACSO Ecuador, 2011.

Téngase presente que la generalidad de los conflictos (no solo los de violencia intrafamiliar) se resuelven al interior de la comunidad. Al respecto relata, por ejemplo, un werken del lof Muco Bajo "[...] yo las veces que me han pegado nunca recurro a la justicia winka [...], no es necesario uno verá que forma de nuevo [...] si uno recurre a la justicia winka, no va a ver justicia porque nosotros somos los enemigos del Estado chileno ¿cómo le vamos a pedir justicia a ellos mismos?". Entrevista realizada el 23 de agosto de 2013, en la comuna de Lautaro, efectuada en el marco del proyecto de investigación "Bases de sustentación de la justicia comunitaria indígena en Chile. Especial referencia al caso mapuche".

"El Lof es la base social dentro de la estructura del territorio mapuche". ÑANCULEF, Juan. La cosmovisión y la filosofía mapuche... op. cit., pp. 48-49.

"Líder de un lof", ibídem, p. 55. 
Por ejemplo, en un lof donde la autoridad principal es una Longka, su sobrina relata cómo se solucionan los conflictos VIF:

\begin{abstract}
Aquí cuando no hay un problema grave, la gente le viene a preguntar en general a la tía Rosa o aquí a mi mami que es su hermana, [...]así la gente dice-iqué van a decir ellas en este problema?- y van a conversar. Se hace una reunión y ahí se decide más o menos cuales son los pasos a seguir [...] si hay un problema entre el matrimonio, va la mamá, el papá, muchas veces los hermanos, $[. .$.$] entonces ahí conversan entre las familias -que pasó, que sucedió aquí, por qué$ ese comportamiento-, entonces buscan el método de salida de ese conflicto ${ }^{30}$.
\end{abstract}

Asimismo, relata un caso real, en que una mujer mapuche "se juntó con un caballero", quien la agredió físicamente y "se le perdonó la primera vez". Luego, cuando volvió a reiterar la conducta, la comunidad reaccionó en conjunto:

[...] conversaron los más mayores y decidieron que debía denunciarse a tribunales y él tenía que irse de la comunidad. Era la única manera de solucionar el problema, la tía podía vivir sola y el resto la podía ayudar sus parientes, sus sobrinos, pero él no podía seguir en la comunidad porque podía cometer algo mayor. Y así se hizo, la tía ahora está sola, efectivamente, siempre se le va a ver, todos tenemos la responsabilidad, pero él se fue de la comunidad, se expulsó porque así nosotros resolvimos el problema $[\ldots]^{31}$.

En relación a las sanciones que se aplican luego de solucionar el conflicto, se pueden identificar dos elementos comunes. Uno de ellos es "el consejo" o lam, que consiste en conversar con la persona que cometió un error, hacerle comprender que hizo algo que no está bien y que el hecho no debe repetirse:

Siempre hay una conversa [...], la gente que comete un error va acompañado de un lam lo que decimos nosotros, de aconsejarlo, decir el que cometió un error no se condena a -tu eres un ladrón, tu eres aquí-. Si no decir -ya, tu cometiste este error, nunca más lo cometas porque somos todos parientes-, osea de alguna forma te sacan, tratan de limpiar tu imagen de esa forma $[\ldots]^{32}$.

Asimismo, la ofensa al prestigio de la familia también se considera una forma de sanción:

El mapuche cuida mucho el tema de los apellidos de la familia, imagínese el hijo de una persona que es intachable en la comunidad, trabajador, una familia sana, buena, y que el hijo le salió malo, le pega a su mujer [...], eso es horrible porque toda la comunidad como que va a condenarlo y eso es muy mal visto en las comunidades mapuches, muy mal visto ${ }^{33}$.

\title{
4. Formas de resolución del conflicto planteado
}

Respecto al conflicto planteado se han dado diversas soluciones. Un primer grupo de respuestas plantea que existe una colisión entre los derechos de la mujer como tal y sus derechos como miembro de un pueblo originario. En este sentido, a nivel normativo, existiría un conflicto entre

30 Entrevista a comunera lof Kurrache, comunidad Ankapi Ñancucheo, realizada el 20 de julio de 2013 en la comuna de Ercilla, Chile. Entrevista efectuada en el marco del proyecto de investigación "Bases de sustentación de la justicia comunitaria indígena en Chile. Especial referencia al caso mapuche". Ibídem.

32 Entrevista a comunero mapuche del lof Temulemu, realizada el 20 de julio de 2013 en la comuna de Traiguén, Chile, en el marco del proyecto de investigación "Bases de sustentación de la justicia comunitaria indígena en Chile. Especial referencia al caso mapuche". Ibídem. 
la Convención de Belem do Pará (que proscribe la violencia contra la mujer), la Ley VIF (que restringe la aplicación de acuerdos reparatorios en sede penal en casos de VIF) y el Convenio 169 (que propugna la consideración de la costumbre indígena en la resolución de conflictos). En este grupo de respuestas, se dan dos posibilidades: que se sostenga la primacía de los derechos de la mujer y que, por lo tanto, no sea posible aplicar los acuerdos reparatorios, o que se aplique el Convenio 169 de la OIT y, por ende la costumbre indígena, permitiendo la aplicación de acuerdos reparatorios pese a su prohibición expresa en la Ley VIF.

Una segunda alternativa, es considerar que dicha colisión de derechos es aparente. Esta es la postura por la que nos inclinamos, en base a los antecedentes que hemos podido recopilar en este estudio y en consideración a que el sistema penal debe entregar a las mujeres víctimas de violencia una respuesta integral, reconociendo sus derechos como mujer y como pertenecientes a un pueblo indígena.

La primera postura, y que reconoce la primacía de los derechos del pueblo indígena por sobre los derechos de la mujer, ha sido adoptada de manera amplia en nuestra jurisprudencia, en base a la aplicación del Convenio 169 de la OIT. Con fundamento en los artículos 9 y 10 del Convenio, la Defensoría Penal Pública asimila los acuerdos reparatorios como salida alternativa al proceso penal, a la costumbre indígena, planteando que el pueblo mapuche utiliza los acuerdos como método de solución de $\operatorname{conflictos}^{34}$. Al respecto, el razonamiento que se hace es el siguiente: "Los acuerdos según el artículo 241 del Código Procesal Penal están permitidos para determinados tipos de delitos que el mismo establece; ahora bien, haciendo aplicación del Convenio 169, es posible extenderlo a otras situaciones haciendo uso del derecho propio o Az Mapu que contiene principios generales que lo guían y gira en torno al restablecimiento del equilibrio; entonces, el razonamiento es $1^{\circ}$ este hecho rompe el equilibrio al interior de la familia, $2^{\circ}$ la misma familia estima que es posible reparar con disculpas públicas y el compromiso de que no volverán a suceder situaciones como ésta, dar por superado el hecho y restablecer las relaciones rotas en su interior. Solicitando en base a ese razonamiento se apruebe el acuerdo reparatorio" ${ }^{\prime 35}$. Este raciocinio, como vimos al comienzo de este artículo, ha sido recogido por gran parte de la jurisprudencia, sobre la base de destacar la supremacía del Convenio 169 por sobre la Ley VIF y estableciendo como criterio probatorio que es un hecho público y notorio que el pueblo mapuche resuelve sus conflictos a través de la conciliación.

Sin embargo, la propia Defensoría reconoce que para "sortear" las dificultades que representa la prohibición de terminar una causa de VIF mediante acuerdos reparatorios, "[el]] punto más débil del caso, [es que] no está probado que haya existido este acuerdo previo, ya sea mediante una asamblea de la comunidad o una reunión familiar [...]. Y segundo, más complejo aún, no se ha presentado prueba pericial que dé cuenta de esta costumbre, de esta forma de resolver los conflictos entre los mapuche ${ }^{\prime \prime 36}$. En este sentido, lo que hace el juez es suponer que se trata de

34 SALAMANCA, Rosario. Pueblos indígenas y acceso a la justicia. Temuco: Programa de derechos indígenas, Instituto de Estudios Indígenas Universidad de la Frontera, p.6. Disponible [en línea] <http://200.10.23.169/trabajados/ SALAMANCA.pdf> [consulta: 1 de octubre de 2013].

35 Defensoría Penal Pública. Comentarios a fallos relevantes en materia de defensa penal de imputados de pueblos originarios. Algunos aspectos para la mejor aplicación del modelo de defensa penal. Informe de análisis jurisprudencial No. 1, Santiago, 2012, p.18. Disponible [en línea] <http://www.biblio.dpp.cl/biblio/DataBank/6367.pdf> [consulta: 13 de marzo de 2014].

Ibídem, p. 17. En el mismo sentido se pronuncian algunos operadores del sistema entrevistados en el marco del proyecto de investigación "Bases de sustentación de la justicia comunitaria indígena en Chile. Especial referencia al caso mapuche". Así por ejemplo, un defensor penal público de la Defensoría Local Mapuche Malleco, entrevistado en dicha comuna, el 21 de agosto 2013, afirma: "No conozco una investigación que me demuestre que eso es así [...] no conozco a nadie que haya escrito, que diga. O sea que son salidas que se buscan al tema por estrategias penales". Así también, un fiscal de la Fiscalía Local de Collipulli, entrevistado en dicha comuna, el 22 de agosto de 2013, señala: "está un poco vacío el argumento de la Defensoría, porque hablan de costumbres en general, pero 
un hecho público y notorio y que da por probado con el solo testimonio de la defensa.

Una segunda postura, que es la que ha defendido el Instituto Nacional de Derechos Humanos $(\mathrm{INDH})^{37}$ y que ha sido recogida de manera minoritaria por la jurisprudencia ${ }^{38}$, se basa en los propios límites que establece el Convenio 169. En efecto, el límite a la aplicación del derecho consuetudinario está señalado de manera expresa en el artículo 9 del Convenio, entendiéndose que los métodos de resolución de conflictos indígenas no deben aplicarse en caso de ser contrarios a los derechos humanos internacionalmente reconocidos, y que en ese caso, la aceptación de la aplicación de un acuerdo reparatorio, significaría una transgresión del derecho de las mujeres a vivir una vida libre de violencia. Por lo demás, también se considera que la situación de violencia es transversal a todas las mujeres. En este sentido, se señala que "no existiría un desarrollo diferente de las dinámicas que se producen en la problemática de la violencia contra las mujeres en el caso de las personas pertenecientes a etnias indígenas, respecto a lo que sucede con el resto de la población". Además, dada la situación asimétrica entre las partes, no puede haber negociación, siendo esta disparidad un fenómeno transversal y que ocurre independientemente de la raza, etnia o nacionalidad de la víctima ${ }^{39}$.

\section{Valoraciones conclusivas: necesidad de una respuesta integral}

En nuestra perspectiva, creemos que la colisión entre los derechos de la mujer indígena es aparente y que la solución que se debe adoptar debe ser integral y con un enfoque participativo. En efecto, todas las medidas que se adopten tendientes a la protección de los derechos de los pueblos originarios y de sus mujeres, deberían ser ideadas, aplicadas, y revisadas con la participación plena y efectiva de las mujeres indígenas pertenecientes a determinado grupo étnico. La política pública en materia indígena no puede ser "monocultural", sino, a lo menos "consultiva" de conformidad con el Convenio 169 y contemplando la posibilidad de darles acceso a los miembros de los pueblos al ejercicio del poder público ${ }^{40}$.

En este sentido, así como no puede invocarse el derecho interno para desconocer las costumbres de los pueblos indígenas y vulnerar sus derechos humanos, tampoco el derecho de los pueblos originarios puede ser justificación para la violación de los mismos. Las mujeres mapuche necesitan que sus derechos sean reconocidos de manera integral, específica y conjunta. Demandan la protección y reconocimiento de sus derechos como mujeres y como miembros de un pueblo. Así, la respuesta que el sistema penal les entrega debe ser funcional a ambas demandas, sin que se sobreponga una demanda sobre la otra. Sin embargo, la solución de nuestros tribunales, propuesta por la Defensoría Penal Mapuche, parece considerar a estas víctimas solo en tanto pertenecientes a un pueblo y no a un género determinado.

En los casos expuestos, se habla de las formas de resolución de conflictos propias del pueblo mapuche. Sin embargo, no se ha acreditado a través de pruebas fehacientes, que el acuerdo reparatorio se identifique con el mecanismo de resolución de conflictos propio del pueblo ma-

hay una gran deficiencia todavía, con señalar concretamente en qué consiste la costumbre, y en probarla".

37 INDH. Amicus curiae causa rol No.388-2012. Temuco, 2012, p. 2. Disponible [en línea] <http://bibliotecadigital. indh.cl/bitstream/handle/123456789/114/violencia-contra-mujer-contexto-indigena-temuco? sequence $=1>$ [consulta: 11 de marzo de 2014].

38 Ver sentencia de la Corte de Apelaciones de Temuco causa Rol 220-2013 de 3 de mayo de 2013 y voto de minoría de la sentencia rol 43-2012, redactado por el ministro Sr. Alejandro Vera Quilodrán.

INDH. Amicus curiae... op.cit, p. 23.

$40 \quad$ VILLEGAS, Myrna. "Entre la exculpación y la justificación. Apuntes de legislación comparada latinoamericana sobre pluralismo jurídico y derecho penal". Revista de Derecho Universidad Austral de Chile, Vol.25, No.2, 2012, p. 179. 
puche. Es muy distinta la dinámica que se da entre las partes, defensor, fiscalía y juez, en la aplicación de la legislación nacional, y la intervención de un tercero imparcial a objeto de aplicar la costumbre indígena.

Debemos entender y reconocer que las distintas culturas y cosmovisiones influyen profundamente en el modo de concebir la justicia. Las prácticas occidentales son en general obligatorias, confrontacionales y sus penas tienen un carácter retributivo. Al contrario del concepto indígena, donde lo que se busca es restablecer el equilibrio, por lo tanto, son por esencia voluntarias, y las sanciones tienen una finalidad de resocializar y reinsertar al agresor en la comunidad. Esto es lo que ocurre en el caso del pueblo mapuche y la violencia intrafamiliar, y de ello dan cuenta los testimonios que hemos recogido en esta investigación.

En este sentido, creemos que una forma de resolución de conflictos respetuosa de los derechos en cuestión, necesariamente debe incluir la intervención real y directa de la comunidad indígena $y / 0$ sus autoridades ${ }^{41}$. El juez de garantía, ajeno a la cosmovisión mapuche, no puede ser quien pase a ocupar el lugar de la autoridad comunitaria.

Por lo demás, el acuerdo entre agresor y víctima, no parece condecirse con la costumbre indígena. En efecto, vimos que no existe una forma de resolución y sanción generalizable propia del Az Mapu, sino que estas varían de un lof a otro, y uno de los pocos factores que se repiten es el recurrir a un tercero que ayude a solucionar el conflicto, cuestión que se aleja de la lógica del acuerdo reparatorio, que es por esencia, un acuerdo entre partes.

La asimilación de una supuesta costumbre mapuche al derecho nacional, a través de un acuerdo reparatorio, no se condice con una solución que proteja los derechos de los pueblos originarios y de las mujeres que de ellos forman parte, lo que es una obligación del Estado de Chile. La respuesta integral que debe dar el Estado se puede lograr mediante una política consultiva que permita la intervención de las comunidades o sus autoridades.

Recibido: 1 de noviembre de 2013

Aceptado: 28 de febrero de 2014

$41 \quad$ En este mismo sentido se ha pronunciado el actual relator especial sobre los derechos de los pueblos indígenas. Consejo de Derechos Humanos. Informe del Relator Especial sobre los derechos de los pueblos indígenas... op. cit., párrs. 29-33. También puede consultarse CORREA, Paula (Ed.). Mediación Intercultural. Estudios sobre Conflictividad y Modelos de Intervención. Santiago: Ministerio de Justicia, 2009. Creemos que una forma mediante la cual se podría otorgar participación a las propias comunidades, sería, por ejemplo, la mediación intercultural. 
